\title{
ANÁLISE DA OBTENÇÃO DE VANTAGENS COMPETITIVAS PARA ARRANJOS PRODUTIVOS LOCAIS: UM ESTUDO EXPLORATÓRIO NO SETOR DE EXTRAÇÃO MINERAL DO ESTADO DA PARAÍBA
}

\section{ANALYSIS OF COMPETITIVE ADVANTAGES TO LOCAL PRODUCTION ARRANGEMENTS: AN EXPLORATORY STUDY IN THE SECTOR OF MINERAL EXTRACTION OF THE STATE OF PARAÍBA}

\author{
Anderson Tiago Peixoto Gonçalves ${ }^{1}$; Gesinaldo Ataíde Cândido ${ }^{2}$ \\ ${ }^{1}$ Universidade Federal do Rio Grande do Norte (UFRN) - RN - Brasil \\ adm.andersontiago@gmail.com \\ ${ }^{2}$ Universidade Federal de Campina Grande (UFCG) - Campina Grande - PB - Brasil \\ gacandido@uol.com.br
}

\begin{abstract}
Resumo
Com o acirramento da competitividade, as organizações têm buscado alternativas que possibilitem a obtenção de vantagens competitivas. Em meio às estratégias adotadas está a formação das chamadas relações interorganizacionais, baseadas em práticas de cooperação produtiva, ou arranjos organizacionais, os quais consistem em parcerias entre atores de natureza econômica, política e social, com intuito de proporcionar resultados positivos em contraposição à atuação de modo isolado. Dentre as configurações que estas relações podem constituir estão os Arranjos Produtivos Locais (APLs), que são concentrações geográficas de organizações produtivas $e$ institucionais em torno de um conjunto específico de atividades econômicas. $O$ objetivo deste artigo é analisar a obtenção de vantagens competitivas com a estruturação de um APL no setor de extração mineral no Estado da Paraíba. Trata-se de uma pesquisa qualitativa, exploratória, bibliográfica e documental, a qual utilizou como instrumentos de coleta de dados dois roteiros de entrevista semiestruturados, baseados em modelos pré-existentes, os quais foram aplicados junto aos representantes dos agentes produtivos e dos agentes institucionais que integram o referido APL. Os dados foram analisados e tratados qualitativamente, através da utilização da técnica de análise de conteúdo. A partir dos resultados obtidos, chegou-se a conclusão de que a estruturação do APL apresenta um grande potencial para conduzir ao incremento de vantagens competitivas no setor de mineração local, mesmo com a presença de pontos problemáticos a serem ajustados, em especial a necessidade de mudança na cultura local, de assistencialista e individualista para uma postura mais proativa e coletiva.
\end{abstract}

Palavras-chave: vantagens competitivas; relações interorganizacionais; arranjos produtivos locais; mineração.

\section{Introdução}

Em um contexto organizacional e um ambiente de negócios cada vez mais mutável e competitivo, tendo como características principais a extrema concorrência, constantes mudanças 
mercadológicas e a necessidade da utilização de novas tecnologias, as organizações precisam rever suas formas de atuação, redefinindo-as quanto aos seus sistemas de produção e à adoção de suas estratégias.

Nesta perspectiva, Jarillo (1988); Machado (2003); Balestrin e Vargas (2004); REDESIST (2004); Leite, Lopes e Silva (2009); Deane (2010); e Mozzato (2010) destacam a importância de serem pensadas novas formas de relações interorganizacionais, através da criação de elos de cooperação produtiva entre as organizações, que venham viabilizar a obtenção de vantagens competitivas. Para Keller (2008) a cooperação interorganizacional aparece como uma necessidade estratégica para os agentes econômicos que operam na economia capitalista, assim como surge o desafio de conciliar a competição e a cooperação.

O Centro de Gestão e Estudos Estratégicos - CGEE (2004) destaca a importância da concepção dessas formas de relações interorganizacionais, os chamados arranjos organizacionais ou arranjos interempresariais (AMATO NETO, 2000), ao afirmar que constituem-se em importante fonte geradora de vantagens competitivas duradouras, principalmente quando estas são construídas a partir do enraizamento de capacidades produtivas e inovativas.

Para Lastres e Cassiolato (2005) a formação dos arranjos organizacionais encontra-se geralmente associada às trajetórias históricas de construção de identidades e de formação de vínculos territoriais, a partir de uma base social, cultural, política ou econômica comum. Segundo os autores, aonde houver a produção de qualquer bem ou prestação de algum tipo de serviço haverá sempre um arranjo organizacional, envolvendo atividades e atores relacionados à aquisição de matérias-primas, máquinas e demais insumos. Contudo, estes formatos organizacionais tendem a se desenvolver, sobretudo, em ambientes produtivos propícios à interação, cooperação, complementaridade, ajuda mútua e geração de confiança.

Neste contexto, diante do grande potencial brasileiro no setor de mineração e da necessidade de gerar o desenvolvimento econômico de regiões atuantes neste segmento produtivo, o Governo Federal em parceria com Governos Estaduais e Municipais vem promovendo programas de incentivo ao desenvolvimento de Arranjos Produtivos Locais - APLs de base mineral, os quais consistem, conforme a Rede Brasileira de Informação de Arranjos Produtivos Locais de Base Mineral - RedeAPLmineral (2014), em conjuntos de empreendimentos e de indivíduos em um mesmo território, atuando em torno de uma cadeia produtiva que tenha como base a atividade extrativa e de transformação mineral.

No Estado da Paraíba, o Governo Estadual lançou o Programa de Desenvolvimento da Mineração Paraibana - PROMIN, com o objetivo de apoiar e incentivar o aproveitamento econômico de minerais, o desenvolvimento da produção da indústria e dos APLs de base mineral. Em vista do potencial econômico e geológico da Microrregião do Seridó, o PROMIN tem levado 
ações de organização e estruturação do APL de minerais de Pegmatitos e Quartzitos, focando o fortalecimento do cooperativismo mineral, resgatando da informalidade os pequenos mineradores (garimpeiros) que sobrevivem da extração e comercialização dos bens minerais, explorados de modo rudimentar e predatório (SETDE, 2011).

O processo de estruturação do APL está em fase de consolidação, através da concepção de uma rede de cooperação, parcerias e ações integradas entre governos, micro, pequenas e médias empresas, universidades, cooperativas, mineradoras e outros interessados. A estrutura produtiva já conta com, pelo menos, 06 (seis) Cooperativas de mineração organizadas e formalizadas nos municípios de Junco do Seridó, Várzea, Nova Palmeira, Pedra Lavrada, Frei Martinho e Picuí, as quais totalizam 477 cooperados ou pequenos produtores que atuam na mineração da região.

Neste sentido, este artigo tem como objetivo analisar a obtenção de vantagens competitivas com a estruturação do APL de Pegmatitos e Quartzitos da Microrregião do Seridó Paraibano. Em busca de atender tal objetivo, foram identificadas as principais barreiras à entrada de agentes produtivos no APL; avaliados os pontos fortes e pontos fracos do processo de estruturação do APL; analisada a percepção do valor das parcerias institucionais no APL; elencados os ganhos esperados ao se consolidar as relações de cooperação no APL; além de estudar como ocorre a relação entre a cooperação e a competição no APL.

Para a coleta de dados da pesquisa foram elaborados dois roteiros de entrevista semiestruturados: o primeiro baseado em um modelo proposto por Mozzato (2010), e o segundo baseado em um questionário da Rede de Pesquisa em Sistemas e Arranjos Produtivos e Inovativos Locais - REDESIST. Tais instrumentos foram aplicados junto a três categorias de entrevistados, quais sejam: os diretores-presidentes das seis Cooperativas constituídas na região do Seridó Paraibano; representantes dos cooperados; e representantes das Instituições de apoio envolvidos no APL. Os dados foram tratados e analisados qualitativamente com a utilização da técnica de Análise de Conteúdo.

Além deste conteúdo introdutório, é apresentada uma breve contextualização sobre as relações inteorganizacionais de cooperação e os arranjos organizacionais. Na sequência, aspectos relacionados ao setor de extração mineral na Paraíba são discutidos. O estudo segue com a exposição dos procedimentos metodológicos, apresentação e análise dos resultados e as considerações finais.

\section{As relações interorganizacionais de cooperação e os arranjos organizacionais}

Nos últimos anos, vários estudos têm abordado sobre os modelos de desenvolvimento econômico e social idealizados em alguns países. Dentre estes trabalhos, estão análises relacionadas ao surgimento das diversas formas de relações interorganizacionais de cooperação produtiva ou os 
chamados arranjos organizacionais, ressaltando o papel da formação destes no desenvolvimento de determinadas economias locais.

As discussões sobre as diversas formas de relações interorganizacionais e seus benefícios têm se intensificado significativamente a partir dos estudos que apontaram o desenvolvimento econômico ocorrido na Terceira Itália e no Vale do Silício (EUA), nas décadas de 70 e 80, respectivamente, originado pela concentração de empresas organizadas em aglomerados, que tinham na proximidade geográfica uma potencial fonte de vantagens competitivas (PORTER, 1989; AMATO NETO, 2000; MACHADO, 2003; CAVALCANTI, 2007; KELLER, 2008; MENDONÇA, 2008; CABRAL JÚNIOR; SUSLICK; SUZIGAN, 2010; LIN; LI; YANG, 2011; MARTIN; MAYER; MAYNERIS, 2011).

O economista Alfred Marshall, em seus estudos com ênfase nos Distritos Industriais ingleses, ao final do Século XIX, foi o pioneiro no reconhecimento das vantagens obtidas por essa concentração espacial de empresas, considerando como forças responsáveis pela formação das aglomerações e pela eficiência das empresas concentradas geograficamente, as chamadas economias externas, compostas pelos seguintes fatores: oferta de mão-de-obra qualificada, implantação de empresas subsidiárias (fornecedores) à atividade principal, e ambiente propício à difusão de conhecimentos, tecnologia e inovação (spillovers) (MARSHALL, 1982; MEDEIROS; MAGALHÃES FILHO, 2007; ERBER, 2008; KELLER, 2008; ARTIS; MIGUELEZ; MORENO, 2011; DRENNAN; KELLY, 2011; LIN; LI; YANG, 2011; MARTIN; MAYER; MAYNERIS, 2011; RENSKI, 2011).

No Brasil, o termo mais utilizado para as novas formas de relações interorganizacionais de cooperação, é o de Arranjo Produtivo Local - APL. Porém, a utilização do termo não está isenta de controvérsias, já que outros são utilizados para expressar o fenômeno dos arranjos organizacionais (SUZIGAN, 2006). Dentre estes termos, podem ser citados: redes de empresas, complexos industriais, clusters regionais e setoriais, parques tecnológicos, polos de desenvolvimento, sistemas produtivos e inovativos locais, cadeias produtivas, distritos industriais, milieu inovador, joint ventures, cooperativas, condomínios industriais, consórcios modulares e cadeias de suprimento (AMATO NETO, 2000; LLORENS, 2001; LASTRES; CASSIOLATO, 2005; LOPES; BALDI, 2005; LEITE; BRITO; OLIVEIRA, 2009; MORI; BATALHA; ALVES FILHO, 2009; DIAS, 2011).

No caso dos APLs, tratam-se de aglomerações ou concentrações geográficas e setoriais de empresas, geralmente de pequeno e médio porte, e instituições de apoio, sejam elas de natureza econômica, política ou social, em torno de um conjunto específico de atividades econômicas, nas quais se estruturam vínculos e relações de interação, interdependência, cooperação e aprendizagem, possibilitando a introdução de inovações, essencial para geração de competitividade e 
sustentabilidade dos seus membros, como também para a promoção do dinamismo econômico local da região em que está inserido (REDESIST, 2004; VASCONCELOS; GOLDSZMIDT; FERREIRA， 2005; SUZIGAN， 2006; GALDÁMEZ; CARPINETTI; GEROLAMO, 2009; VIDIGAL; CAMPOS; TRINTIN, 2009; BRITTO; STALLIVIERI, 2010; SORDI; COSTA, 2010).

Independentemente da forma que o arranjo assuma ou o termo utilizado para defini-lo, é reconhecido, tanto teórica quanto empiricamente, que estas formas de organização vêm auxiliando e tendem a auxiliar empresas dos mais variados tamanhos e, particularmente, as pequenas e médias empresas, a superarem barreiras ao seu crescimento (OLAVE; AMATO NETO, 2001; CROCCO et al., 2003; MEDEIROS; MAGALHÃES FILHO, 2007).

Para Crocco et al. (2003) de um lado a proximidade física das empresas propicia o surgimento de externalidades, pecuniárias e tecnológicas, dentre as quais se destacariam a existência de um mercado de trabalho especializado, de relacionamentos entre produtores, fornecedores e usuários, além de ganhos tecnológicos. E de outro, a proximidade física e cognitiva cria condições para uma interação cooperativa. Além disso, neste ambiente organizacional as ideias são trocadas e desenvolvidas e o conhecimento é compartilhado numa tentativa coletiva de melhorar a qualidade de produtos e processos, ocupar segmentos de mercado mais lucrativos, coordenar ações, e resolver problemas em conjunto.

Inseridas nos arranjos, as micros e pequenas empresas podem aumentar o seu poder de barganha com fornecedores, clientes, distribuidores, e instituições bancárias, participar de feiras e eventos, realizar campanhas de marketing, proporcionar aos funcionários cursos de reciclagem, treinamento e palestras, alcançar maior grau de modernização tecnológica, etc., ou seja, boa parte das dificuldades enfrentadas por estas empresas tendem a ter seus efeitos, se não neutralizados, amenizados em função da ação coletiva (BALESTRIN; VARGAS, 2004).

No entanto, Mendonça (2008) salienta que o fato das empresas estarem agrupadas em um determinado arranjo não garante a geração de vantagens e nem se pode afirmar que os benefícios trazidos por um determinado aglomerado poderão ser obtidos em outros. Acrescenta que os arranjos são diversificados, tendo diferentes graus de desenvolvimento, de articulação, de associativismo, e de integração entre os agentes e as instituições.

Segundo Suzigan (2006), há características distintivas entre os diversos arranjos, as quais são resultantes de vários, tais como: história, evolução, organização institucional, contextos sociais e culturais em que se inserem, impactos sobre a estrutura produtiva, a forma de organização da produção, os processos de aprendizado e a forma de governança local.

\subsection{Os arranjos organizacionais e suas implicações}

Um aspecto comum analisado nas experiências dos arranjos é a capacidade de gerar as chamadas economias externas incidentais, que têm papel fundamental no aumento da 
competitividade. O conceito de economias externas incidentais refere-se àqueles benefícios que as organizações obtêm naturalmente pelo fato de estar operando em uma aglomeração produtiva (MACHADO, 2003; SUZIGAN, 2006; ERBER, 2008; KELLER, 2008).

Suzigan (2006) explica que as economias externas incidentais seriam decorrentes, por exemplo, da existência de um amplo contingente de mão-de-obra especializada; presença e atração de um conjunto de fornecedores especializados; e grande disseminação de conhecimentos e informações, por meio dos chamados spillovers. O autor diz, ainda, que além das economias externas incidentais, os agentes econômicos podem reforçar sua capacidade competitiva por meio das chamadas ações conjuntas deliberadas, tais como: compra de matéria-prima, promoção de cursos de capacitação e formação, contratação de serviços especializados, estabelecimento de centros tecnológicos de uso coletivo, obtendo, conforme Machado (2003), ganhos planejados de modo intencional ou economias internas.

A junção das economias externas incidentais com as alcançadas por ações conjuntas deliberadas, as economias internas, resulta na eficiência coletiva, principal determinante das capacidades competitivas das empresas e da formação dos arranjos (SCHMITZ, 1997; SCHMITZ; NADVI, 1999; ERBER, 2008; KELLER, 2008). Os autores apontam a primeira como sendo a eficiência coletiva passiva, e a segunda como a eficiência coletiva ativa.

Na formação arranjos, tanto a cooperação vertical, desenvolvimento de relações interfirmas entre os diversos segmentos produtivos ao longo da cadeia, como a horizontal, aglomerado espacial ou setorial num mesmo segmento produtivo, podem tornar-se o diferencial competitivo dos seus membros (BAIR; GEREFFI, 2001). Porter (1989) diz que uma vez formado um agrupamento de empresas, os benefícios projetam-se verticalmente e horizontalmente, as informações fluem livremente e as inovações se difundem com rapidez.

Por meio das redes horizontais, as empresas podem coletivamente atingir economias de escala acima da capacidade individual de cada uma; realizar compras conjuntas de insumos; realizar marketing conjunto; e combinar suas capacidades de produção para atender pedidos de grande escala. Enquanto que através das redes verticais, podem especializar-se no seu core business e dar lugar a uma divisão externa do trabalho, mas interna ao local, através da interação entre usuários e produtores (CEGLIE; DINI, 1999). Segundo Balestrin e Vargas (2004), arranjos de cooperação horizontal são aqueles nos quais as empresas mantêm a sua independência, mas optam por coordenar certas atividades específicas de forma conjunta.

Keller (2008) enfatiza as relações interorganizacionais horizontais bilaterais (compartilhamento entre duas firmas) e multilaterais (várias firmas em alguma iniciativa conjunta), afirmando que ambas podem envolver desde a competição acirrada até formas diversas de cooperação. Já em relação às formas de cooperação verticais, o autor afirma que as bilaterais mais 
comuns ocorrem nas relações dos produtores com seus fornecedores quando estes trocam informações a fim de melhorar a qualidade dos componentes ou dos serviços demandados; enquanto que as multilaterais podem ocorrer entre associações que representam segmentos produtivos específicos ao longo da cadeia.

Gitahy et al. (1997) entende que a natureza das relações horizontais difere bastante das relações verticais, na medida em que a concorrência permanece ativa entre empresas que produzem o mesmo bem, dificultando o desenvolvimento de relações de cooperação.

Porém, no tocante a essa coexistência de competição e cooperação nestas formas de relacionamentos, salienta-se que a competitividade pode também ser aumentada por meio de processos de competição dentro do próprio arranjo. Esta competição tem o potencial de aumentar a produtividade, conduzir a direção e o ritmo de inovação e estimular a formação de novos negócios, provocando a expansão e o fortalecimento do arranjo, e gerando crescimento dos membros nele inserido (AMATO NETO, 2000; CORSO; SCHERNER; KINAL, 2004; LEÃO, 2004; VASCONCELOS; GOLDSZMIDT; FERREIRA, 2005; DEANE, 2010).

\subsection{A coexistência entre as relações de cooperação e a competição}

Leite, Lopes e Silva (2009) afirmam que os relacionamentos interorganizacionais constituem uma estrutura em que se manifesta tanto a estratégia de cooperação quanto a de competição. Conforme os autores, o fato das empresas atuarem cooperativamente não implica na exclusão da concorrência entre elas.

Mozzato (2010) completa os autores supracitados afirmando que todos os ganhos advindos da cooperação não eximem a competição, a qual é maior ou menor conforme as diferentes configurações adotadas em função dos diferentes interesses organizacionais, mesmo em ambientes que há a concorrência a cooperação é viável. Frisa-se que a competição interna em um arranjo não pode ser encarada apenas como algo negativo, uma vez que esta força o desenvolvimento e estimula a competitividade das organizações. Foi com este pensamento que Brandenburger e Nalebuff (1996) criaram o termo "Coopetição", definindo-o como um modo das organizações pensarem concomitantemente a cooperação e a competição.

Contudo, estas relações dependem fundamentalmente da confiança na reciprocidade do outro (TUOMELA, 2000). É importante gerar elos de confiança, pois se constitui em um fator necessário para prosperidade, desenvolvimento econômico e eficiência dos arranjos, ou seja, a aptidão para gerar confiança é fundamental para tornar a existência da rede estratégica de cooperação viável (MOZZATO, 2010). Por mais que se admita que as diferentes formas de cooperação constituam-se como estratégias duradouras, há o receio de que estes tipos de relações passem por dificuldades associadas à confiança e seu enraizamento. 
A confiança reflete a convicção de que a palavra de cada membro será cumprida, assegurando consequentemente o cumprimento das obrigações do relacionamento, minimizando o nível de competição entre os membros envolvidos na relação cooperativa (INKPEN, 2000), possibilitando-se, assim, a coexistência da cooperação e da competição. Logo, quanto maior a confiança de que um ato será retribuído, quanto maior a troca entre os agentes, menor a probabilidade de que ocorram comportamentos oportunistas, e maior a probabilidade de que os indivíduos cooperem em benefício mútuo.

Abordado tema central do trabalho, na seção subsequente são discutidos os aspectos relacionados ao setor de extração mineral na Paraíba, antecedidos por uma breve contextualização econômica e social da mineração no Brasil.

\section{Contextualizando a mineração no Brasil}

No contexto econômico, o Brasil detém um dos maiores patrimônios minerais e é um dos maiores produtores e exportadores de minérios do mundo. De acordo com o Instituto Brasileiro de Mineração - IBRAM (2012), o país é o maior exportador (global player) de nióbio, $2^{\circ}$ de minérios de ferro, manganês, bauxita e tantalita, $3^{\circ}$ de grafite, e $4^{\circ}$ de rochas ornamentais. Além disso, no período 2001/2011 o valor da Produção Mineral Brasileira - PMB cresceu aproximadamente 550\%, saindo de US\$ 7,7 bilhões para US\$ 50 bilhões.

A importância da atividade mineral no Brasil é justificável não apenas pela posição de destaque mundial no contexto econômico, mas também pela sua representatividade social, uma vez que, segundo o IBRAM (2012), o total de mão-de-obra empregada na mineração em 2011 alcançou 175 mil trabalhadores. Estudos feitos pela Secretaria Nacional de Geologia, Mineração e Transformação Mineral do Ministério de Minas e Energia mostram que para cada posto de trabalho na mineração, são criadas 13 outras vagas (empregos diretos) ao longo da cadeia produtiva, além dos empregos indiretos.

A região Nordeste, por sua vez, apresenta destaque na mineração brasileira, com uma variada gama de ambientes geológicos, onde estão contidos diversos tipos de depósitos minerais, dentre os quais se destacam pelo volume das reservas, pela quantidade e valor da produção mineral, ou pelo reflexo na cadeia produtiva regional, os seguintes minerais: cromita, ouro, titânio, pedra britada, bentonita, calcário, fosfato, gipsita, magnesita, potássio, rochas ornamentais e sal gema (BEZERRA, 2009b).

Segundo o Anuário Mineral Brasileiro, apresentado pelo Departamento Nacional de Produção Mineral - DNPM (2010), órgão vinculado ao MME, no ano de 2009 a região Nordeste teve participação de $9,5 \%$ no valor total da produção mineral brasileira comercializada, isto é, da 
produção vendida, consumida ou transferida para industrialização, ficando atrás das regiões Sudeste $(51 \%)$ e Norte $(26 \%)$.

\subsection{O setor de extração mineral na Paraíba e a estruturação do APL de base mineral}

A mineração no Estado da Paraíba tem um histórico que data da década de 40, mais especificamente na Microrregião do Seridó, pertencente à Mesorregião da Borborema, com a extração de minerais de pegmatitos e quartzitos, contando na época com incentivos resultantes da cooperação do Governo Brasileiro com as Forças Aliadas durante a $2^{\mathrm{a}}$ Guerra Mundial. Naquela ocasião, foi incentivada principalmente a produção de minerais de berílio, de lítio e de tântalo. Com o fim do conflito, houve uma queda de produção, mas firmou-se na região uma cultura mineral que persiste até hoje (BEZERRA, 2009).

A região do Seridó apresenta uma riqueza mineral significativa, tanto economicamente como no tocante à diversidade de recursos minerais existentes, visto que nela se localizam as principais jazidas de berilo, caulim, espodumênio, feldspato, mica, quartzo, tantalita, columbita, calcários, e gemas coradas do Estado da Paraíba. No entanto, a atividade de extração mineral local sempre foi caracterizada pelo alto índice de informalidade, baixo nível tecnológico, e altos índices de acidentes e de degradação ambiental (SETDE, 2011).

Assim, diante do potencial econômico do Seridó Paraibano e dos problemas existentes na mineração local, foi percebida a necessidade de reestruturar a atividade, quanto à exploração de pegmatitos e quartzitos, minerais industriais presentes em quase toda a região, com a finalidade de, principalmente, favorecer os pequenos mineradores (garimpeiros), os quais exercem a atividade em nível de subsistência. E, na busca por opções de realizar essa reestruturação, foi entendido pelo Governo do Estado da Paraíba, através do PROMIN, que a melhor estratégia para promover o desenvolvimento da atividade seria a estruturação e o fortalecimento do APL de Pegmatitos e Quartzitos da Microrregião do Seridó, com a organização e formalização de seis Cooperativas em municípios com destaque na mineração, seja em virtude da quantidade de depósitos minerais existentes ou da importância da atividade para a população local. Os municípios escolhidos foram Várzea e Junco do Seridó, no Seridó Ocidental; e Pedra Lavrada, Nova Palmeira, Picuí e Frei Martinho, no Seridó Oriental.

Oliveira (2011) salienta que os APLs de base mineral representam um valioso instrumento estratégico de articulação e integração de políticas de apoio ao desenvolvimento regional e local da mineração em pequena e média escala, além de propiciarem condições favoráveis à geração, adaptação, difusão e uso de novas tecnologias, melhorando a gestão e a capacidade produtiva das organizações envolvidas.

Os principais atores envolvidos no APL são as seis Cooperativas constituídas nos municípios citados anteriormente e seus cooperados; o Governo do Estado da Paraíba, através de 
seus órgãos e secretarias; e o Governo Federal, através de Ministérios e outros órgãos. As Cooperativas formam o grupo dos agentes produtivos, enquanto que os demais atores compõem o grupo dos agentes institucionais.

O Quadro 1 apresenta a relação das Cooperativas de mineração da região, os municípios onde estão localizadas, o número de produtores cooperados, e o número de áreas (jazidas) formalizadas ou registradas até o momento.

Quadro 1 - Relação das Cooperativas que integram o APL

\begin{tabular}{|c|c|c|c|}
\hline Cooperativa & Município & $\mathrm{N}^{0}$ de cooperados & $\mathrm{N}^{\circ}$ de áreas formalizadas \\
\hline COOPICUÍ & Picuí & 75 & 03 áreas formalizadas \\
\hline COOPERMINERAL & Frei Martinho & 35 & 03 áreas formalizadas \\
\hline COOPERJUNCO & Junco do Seridó & 180 & $\begin{array}{l}01 \text { área formalizada e } 08 \text { em processo de } \\
\text { formalização }\end{array}$ \\
\hline COOPEVÁRZEA & Várzea & 102 & 01 área formalizada \\
\hline COOMIPEL & Pedra Lavrada & 25 & $\begin{array}{l}02 \text { áreas formalizadas e mais } 01 \text { em processo } \\
\text { de formalização }\end{array}$ \\
\hline COOGARIMPO & Nova Palmeira & 60 & 01 área formalizada \\
\hline
\end{tabular}

Fonte: Pesquisa de campo (2013)

Dentre as Cooperativas, três atuam na extração e beneficiamento de minerais, as localizadas nos municípios de Junco do Seridó, Nova Palmeira e Pedra Lavrada. Já as outras três apenas na extração: Várzea, Picuí e Frei Martinho. Os principais minerais extraídos em Várzea e Junco do Seridó são classificados como rochas ornamentais ou quartzitos. Enquanto que em Picuí, Frei Martinho Pedra Lavrada e Nova Palmeira, municípios situados na Província Pegmatítica da Borborema, região do Seridó na divisa entre os Estados da Paraíba e do Rio Grande do Norte, os minerais extraídos são os chamados pegmatitos.

Tanto as rochas ornamentais como os pegmatitos são considerados minerais industriais que, segundo o DNPM (2009), são todas as rochas e minerais, inclusive os sintéticos, predominantemente não metálicos, que, por suas propriedades físicas ou químicas, podem ser utilizados como matéria-prima, insumo, ou aditivos em processos industriais.

\section{Procedimentos Metodológicos}

O presente estudo constitui-se em uma pesquisa de abordagem qualitativa, e exploratória do ponto de vista de seus objetivos, a qual busca analisar a obtenção de vantagens competitivas a partir da estruturação do APL de Pegmatitos e Quartzitos da Microrregião do Seridó Paraibano. Inicialmente, foi realizada revisão bibliográfica e pesquisa documental, a fim de apresentar os principais conceitos teóricos referentes ao tema central do estudo, bem como as características do seu objeto. Como instrumentos de coleta de dados foram elaborados dois roteiros de entrevista semiestruturados, um baseado no modelo proposto por Mozzato (2010), e outro baseado em um questionário da REDESIST. 
Foram delimitados como sujeitos da pesquisa três categorias de entrevistados, totalizando o número de 18 pessoas: os diretores-presidentes das seis Cooperativas de mineração da região do Seridó; um (01) cooperado com considerável representatividade em cada uma das Cooperativas (lideranças formalmente eleitas, presidentes de associações e/ou sindicatos locais de garimpeiros, diretores comerciais, etc.); e um (01) representante de cada uma das Instituições de apoio consideradas como mais atuantes no desenvolvimento do APL, quais sejam o Ministério do Desenvolvimento, Indústria e Comércio Exterior (MDIC), o Centro de Tecnologia Mineral (CETEM), o Ministério da Integração Nacional (MI), a RedeAPLMineral, a Companhia de Desenvolvimento de Recursos Minerais da Paraíba (CDRM-PB), e o Serviço Brasileiro de Apoio a Micro e Pequena Empresa (SEBRAE-PB).

Em relação à escolaridade dos entrevistados, a maioria dos cooperados possui baixo nível educacional. Quanto aos diretores-presidentes das Cooperativas, 02 possuem curso superior, sendo 01 em economia e 01 em administração; 01 cursa tecnologia em agroecologia; 01 possui ensino médio incompleto; e 02 possuem ensino fundamental incompleto.

O roteiro de entrevista baseado no modelo de Mozzato (2010) foi aplicado junto aos seis cooperados, e o baseado na REDESIST com os seis diretores-presidentes das Cooperativas e os seis representantes das Instituições de apoio. As entrevistas ocorreram entre os meses de agosto e outubro de 2012, as quais tiveram o seu áudio gravado (duração média de 65 min.), com aquiescência dos entrevistados, para posterior transcrição, e à medida que as questões iam sendo respondidas também eram feitas anotações.

Após a aplicação dos instrumentos de pesquisa, os dados foram tabulados e analisados qualitativamente, com a utilização da técnica de Análise de Conteúdo, a fim de:

a) Identificar as principais barreiras à entrada de agentes produtivos no APL;

b) Avaliar os pontos fortes e pontos fracos do processo de estruturação do APL;

c) Analisar a percepção do valor das parcerias institucionais no APL;

d) Elencar os ganhos esperados ao se consolidar as relações de cooperação no APL;

e) Estudar como ocorre a relação entre a cooperação e a competição no APL.

Segundo Bardin (2011), a Análise de Conteúdo consiste em um conjunto de técnicas de análise das comunicações. Para o autor, não se trata de um instrumento, mas de um leque de apetrechos; ou com maior rigor, será um único instrumento, mas marcado por uma grande disparidade de formas e adaptável a um campo de aplicação muito vasto: as comunicações. Acrescenta, ainda, que a Análise de Conteúdo surge como um conjunto de técnicas de análise das comunicações, que utiliza procedimentos sistemáticos e objetivos de descrição do conteúdo das 
mensagens. A sua intenção é a inferência de conhecimentos relativos às condições de produção (ou de recepção), a qual recorre a indicadores (quantitativos ou não).

$\mathrm{Na}$ Análise de Conteúdo busca-se categorizar as unidades de texto (palavras ou frases) que se repetem, inferindo uma expressão que as representem, ou seja, o texto é desmembrado em unidades ou categorias conforme os temas que emergem do texto, e para classificar os elementos em unidades é preciso identificar o que eles têm em comum, permitindo seu agrupamento (CAREGNATO; MUTTI, 2006).

Para discutir os resultados obtidos nos quatro primeiros objetivos foram criadas categorias ou unidades de análise constituídas pelos aspectos respondidos com maior frequência pelos entrevistados, com intuito de tornar os resultados consistentes e agregados. Por fim, foi elaborada a Figura 1 com a compilação das categorias criadas e dos resultados obtidos.

Destaca-se, ainda, que alguns dos trechos significativos derivados de respostas dos entrevistados foram apresentados no texto, para que o leitor tenha acesso direto à informação obtida, e possa se sentir seguro de que a análise foi, de fato, feita sobre as respostas dos respondentes e não sobre impressões que o pesquisador teve durante ou após a pesquisa.

\section{Apresentação e análise dos resultados}

Esta seção apresenta os resultados obtidos após a aplicação dos instrumentos de coleta de dados, a qual está dividida em cinco partes de acordo com os itens mostrados na seção anterior: 4.1 Principais barreiras à entrada de agentes produtivos no APL; 4.2 Pontos fortes e pontos fracos do processo de estruturação do APL; 4.3 Percepção do valor das parcerias institucionais no APL; 4.4 Ganhos esperados ao se consolidar as relações de cooperação no APL; e 4.5 A relação entre a cooperação e a competição no APL.

\subsection{Principais barreiras à entrada de agentes produtivos no APL}

Este item busca identificar os motivos que impedem a adesão de agentes produtivos, os pequenos produtores que atuam na mineração da região do Seridó Paraibano, ao APL, a qual dar-se através da inserção dos mesmos juntos às Cooperativas de mineração já formalizadas e constituídas nos municípios de Junco do Seridó, Várzea, Frei Martinho, Pedra Lavrada, Nova Palmeira e Picuí.

Das entrevistas realizadas junto aos diretores-presidentes das Cooperativas, cooperados e representantes das Instituições de apoio do APL, verificou-se fatores vistos como barreiras, os quais foram agrupados em unidades de análise. Assim, a partir dos fatores citados com maior frequência pelos entrevistados destacaram-se as seguintes unidades: (a) cultura local; (b) perda de exclusividade de mercado; e (c) descrença no Poder Público.

Em um entendimento comum entre as três categorias de entrevistados, a (a) cultura local surge como principal entrave à entrada de agentes produtivos no APL, em decorrência da forte 
resistência às mudanças organizacionais a que se propõem as relações de cooperação. Esta resistência pode ser explicada pela visão individualista dos pequenos produtores, pela falta de informação e conhecimento sobre a cultura cooperativista, e pela falta de percepção das vantagens que podem ser obtidas através da formação de relações desta natureza.

Neste sentido, o diretor-presidente da COOGARIMPO afirmou que:

[...] Boa parte dos cooperados não creem na cooperação, o que dificulta a geração da confiança. [...] Ainda acham que tem que ser aquele assistencialismo, em que os recursos são divididos em partes iguais, não acreditam no cooperativismo, são imediatistas, não creem em trabalhos com resultados a longo prazo.

O diretor-presidente da COOPERJUNCO falou sobre a descrença dos cooperados:

[...] Há essa descrença em virtude da dificuldade de comércio, da vida do garimpeiro ser muito restrita, mas no momento em que tiver mais mercado a situação tende a mudar. [...] Associaç̃oes do passado, que eles acreditaram, não cumpriram com o prometido. [...] Os recursos recebidos por estas associações tiveram destinos desconhecidos.

A segunda unidade que se apresentou com mais força, e que está diretamente relacionada a resistência às mudanças, é o entendimento dos pequenos produtores de que a formação de Cooperativas implica em (b) perda de exclusividade de mercado, isto é, eles veem os possíveis parceiros como concorrentes que reduzirão seu market share. Já a terceira unidade, (c) descrença no Poder Público, decorre do histórico negativo de políticas públicas implementadas no setor mineral da região, e que não mostraram resultados satisfatórios.

\subsection{Pontos fortes e pontos fracos do processo de estruturação do APL}

Como forma de avaliar o processo de estruturação do APL, buscou-se identificar os seus pontos fortes e pontos fracos. Os pontos fortes referem-se aos benefícios que a estruturação do APL, através da organização de Cooperativas, tem possibilitado e tendem a possibilitar aos pequenos produtores. Já os pontos fracos referem-se aos fatores que inibem ou tornam lenta a obtenção destes benefícios por parte dos pequenos produtores. A partir das respostas obtidas foram criadas unidades de análise compostas pelos fatores citados com maior frequência pelos entrevistados.

Quanto aos pontos fortes, as unidades que emergiram do agrupamento dos fatores mais citados foram: (a) aumento da comercialização; (b) ações conjuntas em busca de objetivos comuns; (c) aumento da competitividade; (d) maior proximidade relacional com instituições públicas; (e) formalização da atividade de extração mineral; e (f) desenvolvimento local da região.

Constatou-se que, segundo os representantes das Instituições de apoio, a realização de (b) ações conjuntas é o principal benefício proporcionado pela estruturação do APL, as quais, conforme Schmitz e Nadvi (1999), são chamadas de eficiência coletiva ativa. 
Tanto os diretores-presidentes das Cooperativas como os cooperados indicaram o (a) aumento da comercialização como principal benefício, visto que a estruturação do APL, através de ações pontuais, possibilitará a agregação de valor aos minerais extraídos, a eliminação dos atravessadores como agentes intermediários junto ao mercado, e maior divulgação dos produtos em feiras e eventos.

O diretor-presidente da COOPICUÍ, falou sobre o aumento da comercialização:

[...] Atualmente, a COOPICUÍ vende os minerais extraídos diretamente para as empresas compradoras, pois o principal objetivo na criação das Cooperativas é retirar os intermediários do mercado, os atravessadores.

Já a fala do diretor-presidente da COOMIPEL ilustra a agregação de valor aos minerais extraídos decorrente de uma das ações possibilitadas pela estruturação do APL, que foi a instalação de uma usina de beneficiamento na Cooperativa de Pedra Lavrada:

[...] A albita bruta era vendida para as empresas por $\mathrm{R} \$ 77,00$ a tonelada, mas com o beneficiamento nós vamos passar a vender esse minério por mais ou menos R \$ 300,00. [...] A dolomita bruta era vendida por $\mathrm{R} \$ 22,00$, mas sendo moída no moinho de bola - malha 200 ela pode ser vendida na faixa de $\mathrm{R} \$ 250,00$.

Em relação aos pontos fracos, emergiram quatro unidades de análise: (g) excesso de burocracia nas ações do Poder Público; (h) estrutura de gestão das Cooperativas; (i) falta de capacitação dos cooperados; e (j) falta de continuidade das políticas públicas.

Para as três categorias de entrevistados, o (g) excesso de burocracia nas ações do Poder Público apresenta-se como principal fator inibidor para obtenção de benefícios, principalmente, pela lentidão em colocar em prática as ações previstas pelo PROMIN. Na sequência, surge a (h) estrutura de gestão das Cooperativas, as quais, ainda, apresentam deficiências no fluxo de informações, na sua organização e no planejamento de suas atividades, tanto individuais como conjuntas.

\subsection{Percepção do valor das parcerias institucionais no APL}

A formação de parcerias entre os diversos atores que compõem um arranjo organizacional sejam eles de natureza econômica, social ou política, tem grande impacto no desenvolvimento e no aumento da sua potencialidade competitiva. Nessa perspectiva, buscou-se analisar a percepção de valor das parcerias institucionais para o desenvolvimento e aumento da competitividade do APL em estudo.

Primeiramente, é fundamental identificar quais os atores que compõe o APL, visto que, de acordo com Vasconcelos, Goldszmidt e Ferreira (2005), para a construção de um arranjo é necessária a presença de redes de relacionamentos entre empresas, fornecedores, concorrentes, clientes e instituições de ensino e pesquisa e das associações regionais, pois dessas relações surge a liga da massa que mantém a coesão do Arranjo. 
As principais parcerias existentes no APL são: Governo (Estadual e Federal), Instituições de ensino e pesquisa (Universidade Federal de Campina Grande - UFCG, Instituto Federal de Educação, Ciência e Tecnologia da Paraíba - IFPB e SEBRAE-PB), Clientes, Concorrentes, Órgãos de Apoio Governamentais (Centro de Tecnologia Mineral - CETEM, Departamento Nacional de Produção Mineral - DNPM e Companhia de Desenvolvimento de Recursos Minerais da Paraíba CDRM) e Agentes Financeiros (Banco do Nordeste). O Quadro 2 mostra a percepção da importância destas parcerias nas atividades do APL.

Quadro 2 - Percepção do valor das parcerias institucionais no APL

\begin{tabular}{|c|c|c|c|}
\hline $\begin{array}{c}\text { Categoria de } \\
\text { Entrevistados }\end{array}$ & $\begin{array}{l}\text { Representantes das } \\
\text { Instituições de apoio }\end{array}$ & $\begin{array}{c}\text { Diretores-presidentes das } \\
\text { Cooperativas }\end{array}$ & Cooperados \\
\hline 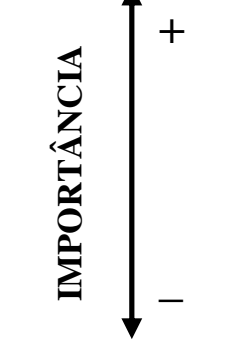 & $\begin{array}{l}\text { Instituições de ensino e } \\
\text { pesquisa/Clientes } \\
\text { Governo/Órgãos de } \\
\text { Apoio/Agentes } \\
\text { Financeiros } \\
\text { Concorrentes }\end{array}$ & $\begin{array}{l}\text { Governo/Órgãos de Apoio } \\
\text { Agentes Financeiros } \\
\text { Clientes/Concorrentes } \\
\text { Instituições de ensino e } \\
\text { pesquisa }\end{array}$ & $\begin{array}{c}\text { Governo/Órgãos de Apoio/ } \\
\text { Agentes Financeiros } \\
\text { Instituições de ensino e } \\
\text { pesquisa } \\
\text { Clientes/Concorrentes } \\
\text { Atravessadores }\end{array}$ \\
\hline
\end{tabular}

Fonte: Pesquisa de campo (2013)

Buscou-se, também, identificar as principais contribuições das parcerias nas atividades do APL. Assim, a partir do que foi coletado junto aos entrevistados foram formadas as seguintes unidades de análise: (a) estímulo à P\&D; (b) fomento e financiamento; (c) promoção e participação em eventos; (d) disponibilização de informações; (e) ações conjuntas; e (f) planejamento estratégico.

Para os representantes das Instituições de apoio, as Instituições de ensino e pesquisa são fundamentais para desenvolvimento e consolidação do APL, assim como os Clientes. Com menor grau de importância estão os Concorrentes. Para esta categoria de entrevistados, as principais contribuições das parcerias são referentes à maior possibilidade de (b) fomento e financiamento, e de promoção de (e) ações conjuntas. Em menor destaque aparece a (c) promoção e participação em eventos.

A valorização das parcerias advindas das Instituições de ensino e pesquisa parte da ideia de mudança tanto de mentalidade como de atitude dos agentes produtivos presentes nestes tipos de arranjo, os quais são descritos por Crocco et al. (2003) como sendo de subsistência, de baixa renda per capita, de baixo nível educacional, com limitada imersão social, implicando em inércia de desenvolvimento.

$\mathrm{Na}$ visão dos diretores-presidentes das Cooperativas, as parcerias institucionais com menor contribuição para o APL são as das Instituições de ensino e pesquisa, um resultado oposto ao que foi constatado junto aos representantes das Instituições de apoio. Tal fato decorre de que pesquisas 
passadas realizadas pelas Instituições de ensino junto às Cooperativas não apresentaram resultados. Já as parcerias apontadas com maior potencial de contribuição estão o Governo, os Órgãos de Apoio e os Agentes Financeiros. Além disso, os diretores-presidentes das Cooperativas entendem que as parcerias têm pouco valor na (f) elaboração de estratégia e definição de objetivos. Enquanto que as maiores contribuições estariam relacionadas ao (a) estímulo à pesquisa e à (c) promoção e participação em eventos.

Ilustrando a contribuição dos Órgãos de Apoio, o diretor-presidente da COOPICUÍ comentou sobre as ações da Companhia de Desenvolvimento de Recursos Minerais da Paraíba CDRM:

[...] A CDRM tem dado apoio na formalização e legalização de áreas de extração. [...] Hoje a atividade tem como se desenvolver, pois antes não tínhamos condição de contratar um Engenheiro de Minas, mas a CDRM tem disponibilizado Engenheiros constantemente para prestar suporte técnico, além de ceder estagiários com formação técnica em mineração.

Quanto ao estímulo à pesquisa, o diretor-presidente da COOPICUÍ disse que:

[...] Estamos trabalhando em parceria com o Instituto Federal de Educação, Ciência e Tecnologia da Paraíba - IFPB, elaborando projetos para redução de impactos ambientais na extração dos minerais, são os chamados Projetos de Recuperação de Área Degradada PRAD.

A percepção do valor das parcerias para os cooperados tem nos Governos, Órgãos de Apoio e Agentes financeiros, os mais importantes aliados na estruturação do APL, seguido das Instituições de ensino e pesquisa. As principais contribuições das parcerias para os cooperados são relacionadas à (c) promoção e participação em eventos.

Vale destacar uma importante relação de "parceria negativa", que se dá entre os atravessadores e os pequenos produtores. $\mathrm{O}$ atravessador é responsável por comprar os minerais direto do garimpeiro a preços baixos e revendê-los com lucro elevado. Tal "parceria" ainda ocorre em virtude do APL ainda não está consolidado, o que faz com que os garimpeiros ainda necessitem dos serviços dos atravessadores.

Neste sentido, o diretor-presidente da COOPICUÍ, comentou que "o atravessador é o nosso maior concorrente, como não ele paga imposto, vende os minerais às empresas por um valor mais baixo do que o da Cooperativa".

\subsection{Ganhos esperados ao se consolidar as relações de cooperação no APL}

Segundo os entrevistados, os principais ganhos que serão obtidos a partir da consolidação das relações de cooperação entre os atores do APL serão: (a) aumento da produtividade; (b) melhor comercialização e marketing; (c) maior capacidade de gestão; (d) redução dos custos; (e) reivindicações comuns; (f) maiores oportunidades de negócios; (g) agregação de valor ao produto; (h) eliminação do atravessador; (i) inovações tecnológicas; e (j) compra de insumos. 
Os cooperados afirmaram que os principais ganhos que serão alcançados, em sequência decrescente de importância, serão: (g) agregação de valor ao produto; (h) eliminação do atravessador; (i) inovações tecnológicas; e (d) redução dos custos. Para os diretores-presidentes das Cooperativas, os ganhos esperados serão os mesmos que os citados pelos cooperados, além de (f) maiores oportunidades de negócios e de (b) melhores condições para a comercialização e marketing.

$\mathrm{Na}$ visão dos representantes das Instituições de apoio, o (a) aumento da produtividade apresenta-se como maior ganho que será possibilitado pela consolidação das relações de cooperação, divergindo do entendimento dos diretores-presidentes das Cooperativas, os quais acreditam que não haverá um impacto considerável quanto a este possível ganho. Quanto ao item (f) maiores oportunidades de negócios, os representantes das Instituições de apoio tem opinião convergente com a dos diretores-presidentes das Cooperativas.

Segundo os representantes das Instituições de apoio, (a) aumento da produtividade, (g) agregação de valor ao produto, (b) melhor comercialização e marketing, e (c) maior capacidade de Gestão, são os principais ganhos esperados com a consolidação do APL, porém entendem que a (d) redução dos custos não terá um impacto tão significativo, quase não ocorrendo quanto ao custo de mão-de-obra, o qual poderá ficar até mais alto decorrente da qualificação profissional que ocorrerá em virtude da presença de universidades e demais instituições de pesquisa e ensino no APL.

\subsection{A relação entre a cooperação e a competição no APL}

A relação entre a cooperação e a competição dentro do APL também foi estudado sob a ótica dos diretores-presidentes das Cooperativas, cooperados e representantes das Instituições de apoio. No entendimento dos diretores-presidentes das Cooperativas e dos cooperados o fato de se formar uma relação de cooperação não elimina a ocorrência da competição entre os agentes produtivos. Segundo os entrevistados, a competição não ocorre apenas entre as Cooperativas, mas também dentro das próprias Cooperativas, onde os cooperados disputam individualmente por maiores rendimentos. Tal comportamento não causa estranheza, uma vez que a divisão dos resultados financeiros é proporcional à participação na produção.

Conforme os representantes das Instituições de apoio, esta competição decorre do fato de que os pequenos produtores locais não estão acostumados a trabalhar de forma coletiva, uma vez que a mineração é desenvolvida como atividade de subsistência por cada garimpeiro. Neste sentido, vale destacar que, para Begnis et al. (2007), mesmo em arranjos com alto grau de comprometimento entre os seus membros, os interesses individuais podem levar a fragilização da relação de cooperação, em virtude deles estarem sujeitos ao comportamento oportunista, o qual pode se dá tanto entre os indivíduos como entre as organizações. 
Apesar disso, os entrevistados entendem que a estruturação do APL é crucial para o desenvolvimento do setor de extração mineral local, e que este tipo comportamento individualista aos poucos vai sendo vencido com a disseminação da cultura cooperativista e do trabalho coletivo. Faz-se necessário frisar que a competição também não pode ser encarada apenas como algo negativo, uma vez que esta força o desenvolvimento e estimula a competitividade das organizações (VASCONCELOS; GOLDSZMIDT; FERREIRA, 2005).

A Figura 1 mostra a compilação das categorias analisadas e dos resultados obtidos para cada um dos objetivos específicos do estudo.

Figura 1 - Compilação das categorias analisadas e dos resultados obtidos

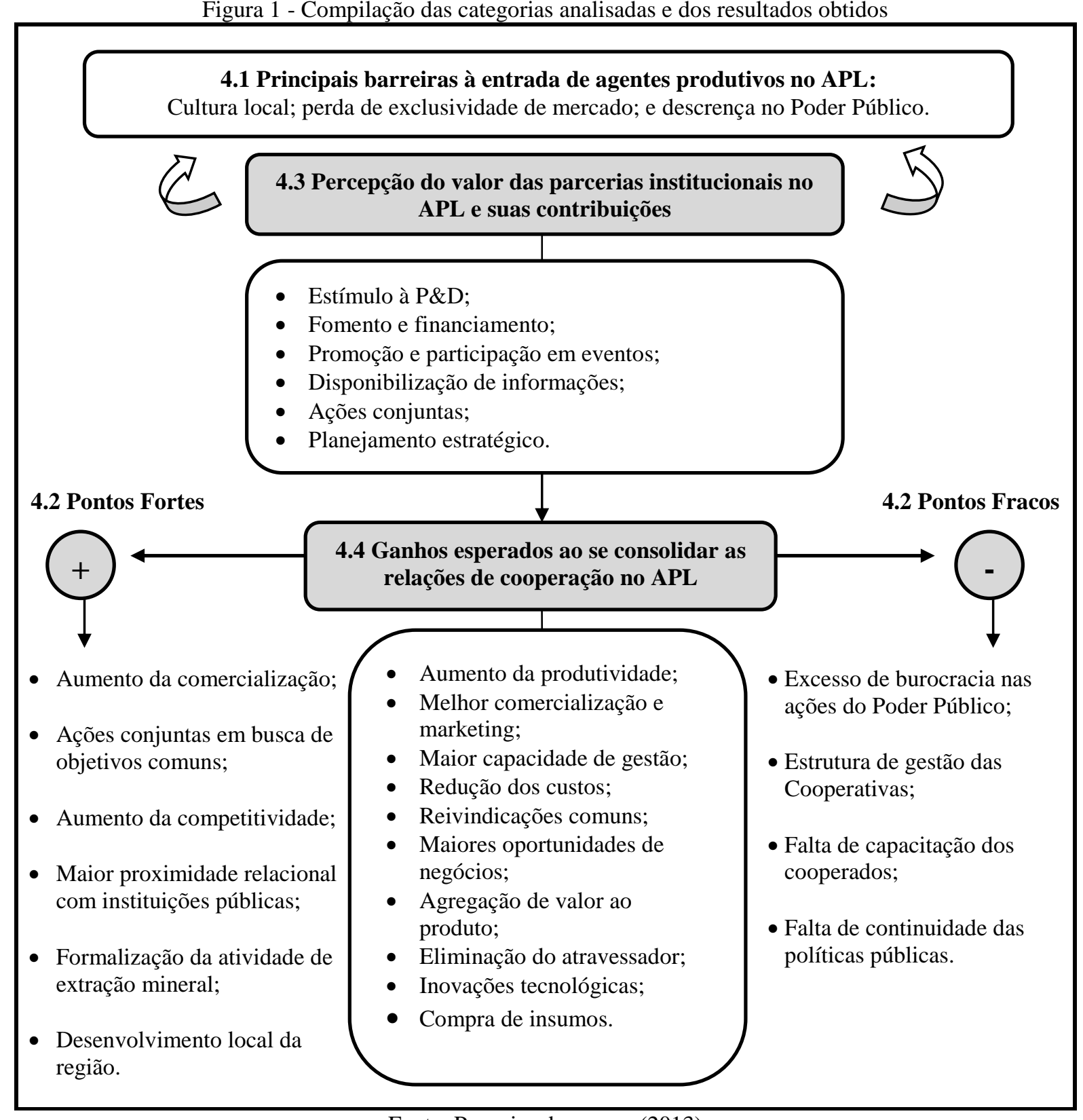

Fonte: Pesquisa de campo (2013)

Portanto, existem barreiras que desestimulam a entrada de novos agentes produtivos no APL, mas que tendem a serem vencidas aos poucos, principalmente em decorrência da atuação das 
parcerias institucionais nas atividades do APL, a fim de que as relações de cooperação se consolidem. Assim, os ganhos esperados serão resultado desta consolidação, a partir da qual serão atenuados os pontos fracos da estruturação do APL, e se elevará a obtenção dos resultados positivos relacionados aos pontos fortes.

\section{Conciserações finais}

Compreender a natureza das relações interorganizacionais de cooperação entre os diversos atores que compõem um arranjo organizacional e o modo como são estruturadas, frente à competição inerente às organizações que atuam no mesmo setor produtivo, torna-se fundamental para o entendimento da dinâmica de um APL em busca da obtenção de vantagens competitivas.

Assim, em busca de analisar a obtenção de vantagens competitivas a partir da estruturação do APL de Pegmatitos e Quartzitos da Microrregião do Seridó Paraibano, o estudo mostrou que a principal barreira que impede a adesão de agentes produtivos ao APL é a cultura local, devido, principalmente, à presença de uma forte resistência às mudanças organizacionais a que se propõem as relações de cooperação.

Os diretores-presidentes das Cooperativas, cooperados e representantes das Instituições de apoio entendem que o aumento da comercialização e a realização de ações conjuntas em prol de objetivos comuns constituem-se como principais pontos fortes do processo de estruturação do APL.

Já os pontos fracos, isto é, os fatores que inibem ou tornam mais lenta a obtenção de benefícios por parte dos pequenos produtores, seriam o excesso de burocracia nas ações do Poder Público; a estrutura de gestão das Cooperativas; a falta de capacitação dos cooperados; e a falta de continuidade das políticas públicas.

O estabelecimento de parcerias é fundamental para a consolidação das relações de cooperação no APL. Neste sentido, as parcerias consideradas de maior importância foram o Governo, os Órgãos de Apoio, os Agentes Financeiros e as Instituições de ensino e pesquisa.

Quanto aos principais ganhos esperados com a consolidação das relações de cooperação, foram citados o aumento da produtividade; a possibilidade de melhor comercialização e marketing; maior capacidade de gestão; redução dos custos; reivindicações comuns; maiores oportunidades de negócios; agregação de valor ao produto; eliminação do atravessador; inovações tecnológicas; e compra de insumos.

Ao analisar os ganhos esperados, entendeu-se que as principais motivações para participar do APL são de cunho econômico. Contudo, o foco no lucro financeiro não é algo necessariamente negativo, porém os agentes produtivos envolvidos no APL podem perder a percepção do sentido da atuação coletiva e virem a ter comportamentos oportunistas, fazendo com que compitam de forma desleal entre eles. 
Verificou-se que a formação das relações de cooperação no APL não extingue a competição entre as Cooperativas que formam o APL, nem entre os seus cooperados, mas esta competição deve ser trabalhada a fim de se tornar fonte de obtenção de vantagens competitivas, dando origem a Coopetição (BRANDENBURGER; NALEBUFF, 1996).

Diante do exposto, conclui-se que a estruturação do APL de Pegmatitos e Quartzitos apresenta um grande potencial para conduzir ao incremento de vantagens competitivas no setor de mineração do Seridó Paraibano e, consequentemente, à promoção do desenvolvimento local da região. No entanto, apresenta pontos a serem ajustados, como o amadurecimento das Cooperativas e a transformação da cultura local assistencialista e individualista em pró-ativa e coletiva.

\begin{abstract}
With competitiveness growing companies have been searching for alternatives that allow them to have advantages. Among the strategies there is the formation of what they call interorganizational relations which are based on practices of productive cooperation or organizational arrangements that consist of partnership among economical, political and social actors in order to provide positive results opposing isolated mode acting. Among the configurations that these relations can build there are the Local Productive Arrangements (LPAs) which are geographical concentrations of productive and institutional organization around a specific group of economical activities. The objective of this article is to analyze the obtainment of competitive advantages with the organization of an LPA in mineral extraction in the state of Paraíba. It is a qualitative, exploratory, bibliographical and documental research which has used two semi-structures interview guides as data collection instrument; these guides were based on pre-existing models which were applied on the productive agents representatives and also on the institutional agents that compose LPA. The data was analyzed and treated quantitatively through the technique of content analysis. From the obtained results it could be concluded that the organization of LPA has a great potential of conducting the increasing in competitive advantage in the mining field even with the presence of problems to be adjusted, specially the need for local culture change from assistentialist and individualist to pro-active and collective
\end{abstract}

Key-words: competitive advantages; interorganizational relations; local productive arrangements; mining.

\title{
Referências
}

AMATO NETO, J. Redes de Cooperação produtiva e clusters regionais: oportunidades para as pequenas e médias empresas. São Paulo: Atlas, 2000.

ARTIS, M. J.; MIGUELEZ, E.; MORENO, R. Agglomeration economies and regional intangible assets: an empirical investigation. Journal of Economic Geography, p. 1 -23, 2011.

BAIR, J.; GEREFFI, G. Local clusters in global chains: the causes and consequences of export dynamism in Torreon's blue jeans industry. World Development, v.29, n.11, p.1885-1903, 2001. crossref

BALESTRIN, A.; VARGAS, L. M. A dimensão estratégica das redes horizontais de PMEs: teorização e evidências. Revista de Administração Contemporânea, ed. especial, p. 203-227, 2004. cross ref

BARDIN, L. Análise de Conteúdo. São Paulo: Edições 70, 2011. 
BEGNIS, H. S. M.; ESTIVALETE, V. de F. B.; PEDROZO, E. A. Confiança, comportamento oportunista e quebra de contratos na cadeia produtiva do fumo no sul do Brasil. Gestão \& Produção, São Carlos, v. 14, n. 2, p. 311-322, maioago. 2007.

BEZERRA, M. S. (Coord.). Plano de Desenvolvimento Preliminar (PDP): Arranjo Produtivo Local de minerais de pegmatito do Rio Grande do Norte e Paraíba. Fundo Setorial CT Mineral, fev. 2009.

Relatório técnico 81 - Perfil do setor mineral do Nordeste e análise das possibilidades de incremento da atividade mineral na região. Projeto de Assistência Técnica ao setor de Energia, nov. 2009.

BRANDENBURGER, A.; NALEBUFF, B. Co-opetição. São Paulo: Rocco, 1996.

BRITTO, J.; STALLIVIERI, F. Inovação, cooperação e aprendizado no setor de software no Brasil: análise exploratória baseada no conceito de Arranjos Produtivos Locais (APLs). Economia e Sociedade, Campinas, v. 19, n. 2 (39), p. 315 358, ago. 2010 .

CABRAL JÚNIOR, M; SUSLICK, S. B.; SUZIGAN, W. Caracterização dos Arranjos Produtivos Locais de base Mineral no Estado de São Paulo: subsídio à mineração paulista. Geociências, São Paulo, v. 29, n. 1, p. 81-104, 2010.

CAREgnATO, R. C. A.; MUTTI, R. Pesquisa qualitativa: Análise de Discurso versus Análise de Conteúdo. Texto Contexto Enferm, Florianópolis, v. 15, n. 4, p. 679-684,2006. crossref

CAVALCANTI, M. B. Fatores impactantes da estruturação dos Arranjos Produtivos Locais: O Caso da Caprinocultura na Região do Cariri Paraibano. 2007. 122 f. Dissertação (Mestrado em Administração Profissional) - Pontifícia Universidade Católica de Minas Gerais, Belo Horizonte, 2007.

CEGLIE, G.; DINI, M. SME cluster and network development in developing countries: the experience of UNIDO, United Nations Industrial Development Organization. PSD Technical Working Papers Series, Viena, 1999.

CGEE - Centro de Gestão e Estudos Estratégicos. Arranjos Produtivos Locais da Paraíba. Brasília, jan. 2004.

CORSO, J. M.; SHERNER, M. L. T.; KINAL, A. P. Cooperação Estratégica em pequenas e médias empresas: um modelo de gestão. Puerto Plata: Pontifícia Universidad Católica Madrey Maestra, 2004.

CROCCO, M. A. et al. Metodologia de Identificação de Arranjos Produtivos Locais Potenciais. Texto para Discussão 212, Belo Horizonte: UFMG/CEDEPLAR, jul. 2003.

DEANE, T. Cooperação Interempresarial: Um Estudo de Caso com quatro Arranjos de Micro e Pequenas Empresas. 2010. 123 p. Dissertação (Mestrado em Engenharia de Produção) - Universidade Federal do Rio de Janeiro, Rio de Janeiro, 2010.

DIAS, C. N. Arranjos Produtivos Locais (APLs) como Estratégia de Desenvolvimento. Desenvolvimento em Questão, v. 9, n. 17, p. 93-122, 2011.

DNPM - Departamento Nacional de Produção Mineral. Economia Mineral do Brasil - 2009: Mineração de rochas e minerais industriais. 2009. Disponível em: <

https://sistemas.dnpm.gov.br/publicacao/mostra_imagem.asp?IDBancoArquivoArquivo=3992 > Acesso em nov. 2012.

. Anuário Mineral Brasileiro. 2010. Disponível em: <

http://www.dnpm.gov.br/relatorios/amb/Completo_2010.pdf > Acesso em out. 2012.

DRENNAN, M. P.; KELLY, H. F. Measuring urban agglomeration economies with office rents. Journal of Economic Geography, v. 11, p. 481-507, 2011. crossref

ERBER, F. S. Eficiência coletiva em arranjos produtivos locais industriais: comentando o conceito. Nova Economia, Belo Horizonte, v.18, n. 1, p. 11-32, 2008.

GALDÁMEZ, E. V. C.; CARPINETTI, L. C. R.; GEROLAMO, M. C. Proposta de um sistema de avaliação do desempenho para arranjos produtivos locais. Gestão \& Produção, São Carlos, v. 16, n. 1, p. 133-151, jan..--mar.2009. crossref

GITAHY, L. et al. Relações interfirmas, eficiência coletiva e emprego em dois clusters da indústria brasileira. Revista Latino-americana de Estudos do Trabalho, México/Brasil, v. 3, n. 6, p. 75-105, 1997. 
INSTITUTO BRASILEIRO DE MINERAÇÃO - IBRAM. Informações e Análises da Economia Mineral Brasileira. 7. ed. [S.1.]: IBRAM, 2012. Disponível em: <http://www.ibram.org.br> Acesso em: set. 2014.

INKPEN, A. C. Learning Through joint ventures: a framework of knowledge axquisition. Journal of Management Studies, v.37, n.7, p.1019-1043, 2000. crossref

JARILLO, J. C. On strategic networks. Strategic Management Journal, v.9, p. 31-41, 1988. crossref

KELLER, P. F. Clusters, distritos industriais e cooperação interfirmas: uma revisão da literatura. Revista Economia \& Gestão, v. 8, n. 16, p. 30-47, 2008.

LASTRES, H. M. M.; CASSIOLATO, J. E. Mobilizando conhecimentos para Desenvolver Arranjos e Sistemas Produtivos e Inovativos Locais de Micro e Pequenas Empresas no Brasil. Glossário de Arranjos e Sistemas Produtivos e Inovativos Locais, $8^{\mathrm{a}}$ Revisão, dez. 2005.

LEÃO, D. A. E. de S. Coopetição: tipologia e impactos no desempenho das empresas da indústria de cachaça de alambique do Estado de Minas Gerais. 2004. 144 p. Dissertação (Mestrado em Administração) - Universidade Federal de Pernambuco, Recife, 2004.

LEITE, M. S. A.; BRITO, A. M.; OLIVEIRA, J. B. Proposta de um framework com traços distintivos como base para a identificação de sistemas de gestão de custos: estudo teórico em formatos organizacionais da mesorregião do semiárido. Gestão da Produção, Operações e Sistemas, ano 4, n. 1, p. 117-13, jan.-mar. 2009.

LEITE, R. S.; LOPES, H. E. G.; SILVA, S. A. D. A Estratégia em Relacionamentos Coopetitivos: um estudo do Arranjo Produtivo de Nova Serrana. Revista Brasileira de Gestão de Negócios, v. 11, n.30, p. 65-78, 2009.

LIN, Hui-Lin; LI, Hsiao-Yun; YANG, Chih-Hai. Agglomeration and productivity: Firm-level evidence from China's textile industry. China Economic Review, v. 22, p. 313-329, 2011. crossref

LOPES, F. D.; BALDI, M. Laços Sociais e Formação de Arranjos Organizacionais Cooperativos: Proposição de um Modelo de Análise. Revista de Administração Contemporânea, v. 9, n. 2, p. 81 -101, 2005. cross ref

LORRENS, A. F. Desenvolvimento econômico local: caminhos e desafios para a construção de uma nova agenda política. Rio de Janeiro: BNDES, 2001.

MACHADO, S. A. Dinâmica dos Arranjos Produtivos Locais: um estudo de caso em Santa Gertrudes, a nova capital da cerâmica brasileira. 2003. 145 p. Tese (Doutorado em Engenharia de Produção) - Escola Politécnica da Universidade de São Paulo, São Paulo, 2003.

MARShall, A. Princípios de economia: tratado introdutório. São Paulo: Abril Cultural, Série Os Economistas, 272 p., 1982.

MARTIN, P.; MAYER, T.; MAYNERIS, F. Public support to clusters: A firm level study of French Local Productive Systems. Regional Science and Urban Economics, v. 41, p. 108 -123, 2011. cross ref

MEDEIROS, J. J.; MAGALHÃES FILHO, O. M. Apoio Governamental ao Desenvolvimento de Arranjos Produtivos Locais e suas Consequências para os Aglomerados Produtivos Vizinhos. In: ENCONTRO DA ASSOCIAÇÃO NACIONAL DE PÓS-GRADUAÇÃO E PESQUISA EM ADMINISTRAÇÃO - ENANPAD, 31., 2007, Rio de Janeiro. Anais ... Rio de Janeiro - RJ, 2007.

MENDONÇA, F. M. Formação, desenvolvimento e estruturação de Arranjos Produtivos Locais na Indústria tradicional do Estado de Minas Gerais. 2008. 266 p. Tese (Doutorado em Engenharia de Produção) - Universidade Federal do Rio de Janeiro, Rio de Janeiro, 2008.

MORI, C. de; BATALHA, M. O.; ALVES FILHO, A. G. Abordagens espaço-relacional de organização da produção em estudos de atividades de produção agroindustrial no Brasil. Revista Brasileira de Gestão e Desenvolvimento Regional, Taubaté, v. 5, n. 3, p. 94 - 115, set.-dez. 2009.

MOZZATO, A. R. Relações Interorganizacionais: Cooperação e Competição como Vantagem Competitiva para o Arranjo Produtivo de Gemas e Pedras Preciosas de Soledade. In: ENCONTRO DE ESTUDOS ORGANIZACIONAIS DA ANPAD - ENEO, 6., 2010, Florianópolis. Anais ... Florianópolis - SC, 2010. 
OLAVE, M. E. L.; AMATO NETO, J. Redes de cooperação produtiva: uma estratégia de competitividade e sobrevivência para pequenas e médias empresas. Gestão e Produção, v.8, n.3, p. 281-303, 2001. cross ref

OLIVEIRA, J. M. F. (Coord.). Avançar e melhorar na organização e modernização dos APLs de base mineral. Perspectiva Mineral, Ano III, SGM/MME, nº 5, 2011.

PORTER, Michael. A vantagem competitiva das nações. Rio de Janeiro: Campus, 1989.

REDEAPLMINERAL - Rede Brasileira de Informação de Arranjos Produtivos Locais de Base Mineral. APLs de Base Mineral. 2014. Disponível em: < http://www.redeaplmineral.org.br> Acesso em abr. 2014.

REDESIST - Rede de Pesquisa em Sistemas e Arranjos Produtivos e Inovativos Locais. Políticas para promoção de Arranjos Produtivos e Inovativos Locais de Micro e Pequenas Empresas: vantagens e restrições do conceito e equívocos usuais. 2004. Disponível em: <http://www.redesist.ie.ufrj.br> Acesso em fev. 2012.

RENSKI, H. External economies of localization, urbanization and industrial diversity and new firm survival. Papers in Regional Science, v. 90, n. 3, p. 473-503, 2011. crossref

SCHMITZ, H. Collective efficiency and increasing returns. IDS Working Paper 50. Institute of Development Studies, University of Sussex, Brighton, 1997.

1999. cross ref

; NADVI, K. Clustering and industrialization: introduction. World Development, v.27, n.9, p.1503-1514,

SETDE - Secretaria de Turismo e Desenvolvimento Econômico do Estado da Paraíba. Governança do APL de Pegmatitos PB/RN. In: Conferência Brasileira de Arranjos Produtivos Locais, 5. 2011, Campina Grande.

SORDI, J. O.; COSTA, M. A. M. Identificação de atores do conhecimento e suas atividades no contexto de Arranjos Produtivos Locais. Gestão \& Regionalidade, v. 26, n. 77, p. 88-98, 2010. cross ref

SUZIGAN, W. (Coord.). Identificação, mapeamento e caracterização estrutural de arranjos produtivos locais no Brasil. Rio de Janeiro: IPEA, 2006.

TUOMELA, R. Cooperation: a philosophical study. Dordrecht: Kluwer Academic Publishing, 2000. crossref

VASCONCELOS, F. C.; GOLDSZMIDT, R. G. B.; FERREIRA, F. C. M. Arranjos Produtivos. GV Executivo, v. 4 , n. $3,2005$.

VIDIGAL, V. G.; CAMPOS, A.C.; TRINTIN, J. G. Interação, cooperação e ações conjuntas no arranjo produtivo local (APL) de confecção de Maringá. Acta Scientiarum. Human and Social Sciences, Maringá, v. 31, n. 2, p. 123-129, 2009.

\section{Dados do autores}

Nome completo: Anderson Tiago Peixoto Gonçalves

Filiação institucional: Universidade Federal do Rio Grande do Norte (UFRN)

Departamento: Administração

Função ou cargo ocupado: Professor Substituto da Universidade Federal Rural do Semiárido

(UFERSA)

Endereço completo para correspondência: Rua Fernando Cunha Lima, 1845, Cristo, João Pessoa-

PB

Fone: (083) 98860-6164

E-mail:adm.andersontiago@gmail.com

Nome completo: Gesinaldo Ataíde Cândido

Filiação institucional: Universidade Federal de Campina Grande (UFCG)

Departamento: Administração

Função ou cargo ocupado: Professor Titular da Universidade Federal de Campina Grande (UFCG) 
Endereço completo para correspondência: Av. Aprígio Veloso, 882, Bairro Universitário, Campina Grande-PB

Fone: (083) 2101-1217

E-mail: gacandido@uol.com.br / gesinaldo@cnpq.br

Submetido em: 18-06-2015

Aceito em: 14-09-2015 